\title{
TEMPOS DE OURO: \\ uma análise sobre a formação espacial de Israelândia-GO
}

\author{
GOLD TIMES: \\ an analysis about the space formation of Israelândia-GO \\ LES TEMPS D'OR: \\ une analyse de la formation spatiale d'Israelândia-GO
}

\author{
Hyago Ernane Gonçalves SQUIAVE ${ }^{1}$ \\ Dimas Moraes PEIXINHO
}

\section{Resumo}

A dinâmica espacial na perspectiva de espaço geográfico, permite a compreensão dos diferentes usos que estão contidos na conformação espacial. Os usos podem estar associados às condições de apropriação da natureza, que por sua vez a transforma em território usado. A formação espacial é um resultado de espaço produzido. A partir dessa perspectiva procurou se compreender a formação espacial de Israelândia (GO), que tem uma constituição a associada aos garimpos rudimentares do século XVIII. Assim, a interpretação recorreu ao tempo de longa duração para analisar a conformação espacial atual desse município do Oeste goiano.

Palavras-chave: Espaço; Israelândia - GO; Mineração.

\begin{abstract}
Spatial dynamics at the perspective of geographic space allows the understanding of the different uses that are contained in spatial conformation. Uses may be associated with conditions of appropriation of nature, which in turn transforms it into used territory. Spatial formation is a result of one space produced. From this perspective we sought to understand the spatial formation of Israelândia (GO), which has a constitution associated with the rudimentary mining of the eighteenth century. Thus, the interpretation used the time of long duration to analyze the current spatial conformation of this municipality of the west of Goiás.
\end{abstract}

Key-words: Space; Israelândia - GO; Mining.

\section{Résumé}

La dynamique spatiale dans la perspective de l’espace géographique, permets la compréhension des différents usages qui sont contenus dans la conformation spatiale. Les usages peuvent être associés aux conditions d`appropriation de la nature. Cette appropriation la transforme la nature en territoire utilisé. La formation spatiale est un résultat d’espace produit. Partant de cette perspective, la compréhension de la formation spatiale de Israelândia (GO) a été analysée. Celle-ci a une constitution associé à l’orpaillage rudimentaire du XVIIIe siècle. Ainsi, l’interprétation a fait recours au temps de longue durée pour l`analyse de la conformation spatiale de cette municipalité du sud-ouest de Goiás.

Mots-clés: l'espace ; Israelândia - GO ; l'exploitation minière.

\footnotetext{
${ }^{1}$ Doutorando do Programa de Pós-Graduação em Geografia da Universidade Federal de Jataí, Jataí-GO. E-mail: hiagoernane@gmail.com

2 Professor Adjunto do Programa de Pós-Graduação em Geografia da Universidade Federal de Jataí, Jataí-GO. E-mail: dimaspeixinho@yahoo.com.br
} 


\section{INTRODUÇÃO}

Pensar a lógica da formação espacial de um determinado lugar, requer conexões entre os elementos constitutivos que foram fundamentais para a materialidade que se encontra no presente. Partimos então da ideia que a geografia estuda o espaço geográfico. Sendo assim, a busca pelas conexões existentes na transformação do espaço de primeira natureza gerando uma segunda natureza (espaço produzido), pode ser um o resultado das relações sócio espaciais.

Partindo do princípio que a formação espacial é o espaço produzido, Isnard (1982, p

25), diz que "Não há sociedade sem um espaço que lhe seja próprio, no qual as gerações se sucedem numa continuidade tal que se realiza uma identificação entre um povo e seu território". Ou seja, a formação espacial está diretamente ligada com as atividades humanas desenvolvidas através de suas necessidades de transformar o espaço. Moreira (1982, p. 2), relata que o "espaço geográfico é parte fundamental do processo de produção social e do mecanismo de controle da sociedade". Seguindo essa perspectiva, Santos (2014, p.3), afirma que o espaço é, "um conjunto de formas contendo cada qual frações da sociedade em movimento. As formas, pois, têm um papel na realização social”. E, ainda, segundo esse autor (2014), o espaço deve ser compreendido como um conjunto indissociável, onde, de um lado temos um arranjo de objetos sejam eles naturais, sociais ou geográficos, e por outro lado a vida que os preenche e os anima, sendo, pois, a sociedade em movimento.

Assim, ao compreender o uso do território, está se compreendendo a sua historicidade. De acordo com Silveira (2011), o território usado abrange tudo aquilo que o constitui materialmente;

Por isso o território usado é tudo aquilo que o constitui materialmente, isto é, as infraestruturas que chamamos sistemas de engenharia, a agricultura, a indústria, o meio construído urbano, as densidades demográficas e técnicas, mas também o que o constitui imaterialmente, as ações, normas, leis, culturas, movimentos da população e fluxos de toda ordem, incluindo ideias e dinheiro (SILVEIRA, 2011, p. 155).

Ao analisarmos o fenômeno que estamos estudando, precisamos fazer um esforço para entender a constituição do território, ou seja, entender o como, onde, por quem, porquê, e para que o território é usado. (Silveira, 2011).

Metodologicamente a geo-história possibilita uma análise dos diferentes usos da conformação espacial em um curto, médio ou longo período de tempo, onde, a geografia em conjunto com a história se unem para compreender um determinado fenômeno utilizando um 


\section{Tempos de Ouro: \\ uma análise sobre a formação de Israelândia-GO}

Hyago Ernane Gonçalves SQUIAVE; Dimas Moraes PEIXINHO

recorte temporal e espacial. Portanto, é pensar o espaço em perspectiva temporal, buscando no tempo, uma explicação para a organização socioespacial.

O recorte temporal depende do recuo necessário para compreender como uma dada realidade se materializa no presente. Nesse sentido, as pesquisas que propõem uma investigação que tem no tempo de maior duração (longa ou média) seu fenômeno, precisam de recursos teórico-metodológicos que se adequem a esse tipo de análise.

É importante lembrar que, como afirma Abreu (2006, p. 240), “pensar o passado do espaço não significa fazer geografia antiquária. Significa buscar em tempos já idos as chaves de interpretação do presente". Portanto, não se tratar de tomar "tempos congelados" em um sitio espacial como fenômenos que se acumulam sem participação na realidade atual. É, então, resgatar os fatos e não isolá-los.

A partir dessas orientações teórico-metodológicas, o objetivo desse trabalho é apresentar, ainda que de forma inicial, uma análise sobre o município de Israelândia, situado no oeste goiano, que teve na sua ocupação originária na exploração mineral nas primeiras décadas do século XVIII, período bandeirante.

\section{AS DESCOBERTAS DAS MINAS DE GOIÁS}

As descobertas das minas em Goiás vêm do final do século XVII, mas sua exploração só foi iniciada no século seguinte, por volta dos anos 1725/26. A exploração mineral no Brasil, assim como as outras fases (cana, café, pecuária), dependia das condições locais de produção e também do mercado internacional com a compra de tais mercadorias (Prado Junior, 2011). O nosso objetivo aqui não é discutir todo esse processo, mas focar nos aspectos da mineração, especialmente em Goiás, pois precisamos desse arcabouço para demonstrar a pesquisa aqui apresentada.

A busca por minerais, na sua primeira fase, foi constituída pelas chamadas" bandeiras descobridoras", aonde predominavam as "empresas particulares" com o aval e apoio da Coroa Portuguesa. Esse movimento de identificação de oportunidades produtivas, formadas por apressamentos de índios, que eram escravizadas e enviados para as fazendas paulistas ou para os engenhos nordestinos, e a busca de ocorrências de minerais, marca as primeiras tentativas de explorar os sertões do território colonial.

Com as descobertas das minas nos gerais, no final do século XVII, pelos bandeirantes houve um grande fluxo populacional para o interior do território colonial, despertando a 
Hyago Ernane Gonçalves SQUIAVE; Dimas Moraes PEIXINHO

cobiça não só dos "aventureiros", mas também da Coroa que pretendia controlar a exploração das riquezas recém descobertas. O conflito crescente entre os descobridores -os Bandeirantes e a Coroa geraram uma disputa pelo controle das minas, que desaguou na chamada guerra dos emboabas. A Coroa não só conseguiu se impor nessa disputa, efetivando a presença do aparato estatal na colônia, como estabeleceu uma nova lógica para a sua exploração. Essa presença no controle sobre as minas descobertas nos gerais produziu um efeito com duas consequências mais imediatas: produziu uma dispersão das bandeiras pelo território que, motivado pelas descobertas, avançam sobre novas áreas, ainda, não controladas pela Coroa mas uma vez com novas descobertas buscavam o reconhecimento de Lisboa para a sua exploração.

As descobertas das minas em Mato Grosso e em Goiás, território da província de São Paulo, exemplifica essa nova lógica. Apesar de ser uns feitos dos bandeirantes, eles só puderam explora-las com a anuências da Coroa. Assim, ao mesmo tempo que a metrópole atendia os interesses dos descobridores, eles reconheciam os interesses da Coroa com o pagamento dos impostos, que conforme os registros históricos nem sempre pagos conforme pretendia a administração colonial. Esse aspecto é importante para se compreender que entre a descoberta e o início da exploração há um intervalo que passa pela concessão das explorações das minas descobertas.

As minas dos goyases foram "descobertas" no final do século XVII, no ano de 1682 pela bandeira de Bartolomeu Bueno da Silva, o Anhanguera (pai) e teve o início da sua exploração a partir de 1723, com a vinda da bandeira do Anhanguera filho.

Aqui Bartolomeu Bueno da Silva (pai) não foi o primeiro a pisar em terras goianas, mas, foi o primeiro a passar por Goiás com a intenção de se fixar. Por volta de 1682, organizou uma bandeira a fim de capturar índios para o trabalho escravo e encontrar riquezas minerais. Nesta expedição, Bueno levava consigo o filho que também portava o mesmo nome: Bartolomeu Bueno da Silva, com doze anos de idade. (Palacín, 1994).

Bueno (pai), encontrou algumas tribos indígenas e conseguiu observar que as índias andavam com folhetos de ouro no pescoço. Bueno era um homem obstinado, de acordo com alguns autores da história de Goiás, Bueno preferia morrer do que voltar a São Paulo fracassado. Logo, um fato marcou a história goiana. Bueno teria ateado fogo num prato de aguardente, dizendo que, se os índios não mostrassem onde teria encontrado o ouro, iria 
colocar fogo nos rios. Por esta atitude Bueno ficou batizado com o nome de Anhanguera, que significa Diabo Velho.

Os índios todos desesperados não se hesitaram em contar onde se encontrava os minerais. Foi aí que Bueno (pai) descobriu as minas em Goiás. Logo, voltou a São Paulo levando amostrar de ouro encontradas por aquele território.

Com a queda da cana-de-açúcar, a Coroa Portuguesa abriu os seus olhos para a procura de ouro e por gentios. Cronologicamente, foi descoberto ouro em Minas Gerais no século XVII e em Mato Grosso e Goiás a descoberta também foi no século XVII, porém a exploração se iniciou no século XVIII. O período do ouro no Brasil na verdade foi o terceiro grande período autônomo da formação econômica brasileira, e, em alguns aspectos é considerado o mais importante que os ciclos do pau-brasil e do açúcar. Segundo Palacín (1994);

Ao se descobrir o ouro no Brasil nos últimos anos do século XVII, este produto passou, imediatamente, a ocupar o primeiro lugar na preferência das autoridades e do povo. Isto se devia, em grande parte, à mentalidade mercantilista, que, durante algum tempo, identificou a riqueza com a posse dos metais preciosos. (PALACÍN, 1994, p. 16).

E continua;

Por isso, no Brasil organizou-se logo uma hierarquia de produção: os territórios de minas deviam dedicar-se exclusivamente - ou quase exclusivamente - à produção de ouro, sem desviar esforços na produção de outros bens, que poderiam ser importados. (PALACÍN, 1994, p. 16).

Bartolomeu Bueno da Silva (pai) não regressou para a exploração das minas em Goiás. Porém, o filho de mesmo nome é quem vai organizar uma nova expedição para encontrar os lugares em que o pai teria descoberto o ouro. A Bandeira organizada por Bueno data em 1722. Organizou todos os documentos junto a Coroa Portuguesa, e lá se vai o segundo Bueno na tentativa de encontrar o lugar em que esteve com o pai.

Por três anos andaram erroneamente pelo território goiano. $\mathrm{O}$ intuito era chegar onde hoje é a Cidade de Goiás - GO, nas margens do rio Vermelho. Porém, perderam o norte e bagando mais ao oeste se chegou aos rios Claro e Pilões. Depois, reorganizaram o trajeto e finalmente conseguiram encontrar o lugar em que pretendia no ano de 1725, fundando o arraial de Sant'Anna. 
Com estas descobertas e início das explorações das províncias minerais (ouro e diamantes), no atual estado de Goiás, entre 1722 e 1725, pela bandeira de Bartolomeu Bueno, Anhanguera filho, que seguindo as orientações do Anhanguera pai, chega à região e assume o controle da exploração mineral e dá início ao seu povoamento colonial.

D. Rodrigo era o governador da Capitania de São Paulo a qual Goiás pertencia no início da exploração. Ele forneceu o direito de exploração mediante a pagamento de impostos a Bueno, além de fornecer sesmarias.

As minas em Mato Grosso já eram exploradas neste período. Para se chegar até elas era preciso percorrer grandes caminhos fluviais, o que impossibilitava em algumas épocas. Então, em 1736 foi determinado que abrisse uma estrada real que ligava a Cuiabá a Goiás, de encontro com outra estrada real que descia até São Paulo. É nesta trilha que vai surgir o arraial de Pilões, marco inicial para a cidade de Israelândia - GO atual.

\section{FORMAÇÃO ESPACIAL DE ISRAELÂNDIA}

A formação socioespacial do que é hoje o município de Israelândia - GO está associada aos processos da exploração mineral do século XVIII. Esse povoamento formou com a descobertas de algumas minas, as margens dos rios Claro e Pilões, no trajeto da estrada real, construída para ligar as minas de Cuiabá a São Paulo, passando por Goiás. Nessa localidade se erigiu um arraial chamado Bomfim no ano de 1746, que três anos mais tarde foi destruído pelos índios caiapó. (Pohl, 1986; Silva, 2002; Palacín, 1994; Bertran, 1988).

O povoamento inicial dessa região associado ao processo da mineração "viveu" períodos de atrações e esvaziamentos seguindo um ciclo das descobertas e decadências das minas. Porém, mesmo com esse processo cíclico, a civilização do ouro, como afirma Bastide (1975, p.117), moldou a urbanização brasileira, diferente da civilização do açúcar, porque "o ouro prendia os homens às zonas auríferas".

Como o ouro prendia os homens as zonas auríferas e mesmo com a destruição do povoado do Bomfim, ainda, restaram algumas pessoas praticando a mineração. A Coroa Portuguesa procurando controlar o contrabando das pedras preciosas decidiu proibir a mineração na região. A exploração só seria feita mediante a um contrato com pagamento de impostos baseado no número de escravos que trabalhamos nas minas, e que deveria ser pelo menos 200 homens. 


\section{Tempos de Ouro: \\ uma análise sobre a formação de Israelândia-GO}

Hyago Ernane Gonçalves SQUIAVE; Dimas Moraes PEIXINHO

A partir dessas condições, no ano de 1749, os Irmãos Joaquim e Felisberto Caldeira Brant, que, já possuíam contratos para extração de diamantes nas Minas dos Gerais, sabendo dos boatos que se espalhavam sobre o descobrimento de ouro e diamante na região dos rios Claro e Pilões decidem formalizar um contrato com a Coroa Portuguesa para a exploração nesses rios. Segundo Pohl (1986);

Gomes Freire de Andrade, que exercia o governo de todas as capitanias do Sul, viajou no ano de 1749 para Goiás, para firmar contrato sobre as lavras 67 de diamantes descobertas no Rio Claro e em Pilões, onde trabalhavam 200 escravos. Mas, comparativamente com as despesas necessárias, a produção era pouca e os contratantes logo regressaram para Minas Gerais. (POHL, 1986, p. 132).

Devido ao aumento na produção do ouro e a facilidade no contrabando, juntamente com a dificuldade do governo em controlar tais problemas, a Coroa Portuguesa decidiu desmembrar Goiás e Mato Grosso de São Paulo por volta de 1744, tornando os dois estados Capitanias próprias. “A capitania de Goiás, foi criada pelo alvará de 8 de novembro de 1744, que a desmembrou da de São Paulo, tornando a independente desta" (SILVA, 2002, p. 181).

Em 1749 o trabalho de exploração dos irmãos Brant é iniciado. O que ainda existia do arraial de Bomfim foi herdado para uma nova povoação que fora denominada de Arraial de Pilões as margens do rio Claro e Pilões. Esta povoação abrigava os escravos e também um destacamento militar do governo que impedia a exploração por forasteiros nas áreas delimitadas do contrato. Porém, a mineração pelo contrato dos irmãos Brant teve vida breve no rio Claro e Pilões, de acordo com Santos (1978);

Na mineração de Pilões e Rio Claro, em Goiás, de que era administrador Joaquim Caldeira Brant, o contrato só teve perdas pela falta de diamantes suficientes. Nos dois primeiros anos o que extraiu não chegou para pagamento das despesas, acrescendo que, não havendo ali terreno para a mineração no tempo das águas, porque os serviços se empreendiam nos leitos de rios sem gupiaras e tabuleiros diamantinos, nesta estação não tinha o contrato onde empregador de modo lucrativo dos duzentos escravos capitados, entretanto que por eles pagava anualmente a avultada capitação ajustada. Nestas circunstâncias, requereu o contratador uma alteração nas condições do contrato, e por ordem de 30 de novembro de 1750 ficou o governador autorizado a entrar em novo ajuste com o contratado. (SANTOS, 1978, p. 123).

Os irmãos Brant ficaram pouco mais de dois anos no arraial de Pilões. Logo, conseguiram junto ao governo uma quebra no contrato alegando muitos prejuízos e se 
retiraram de Pilões com destino a Serro Frio (arraial de Tijuco). A região que estava ocupada sofre um esvaziamento, porém, continuava a habitar ali os guardas do destacamento militar. As terras delimitadas continuaram com a proibição para a exploração de ouro e diamante. Passados aproximadamente cinquenta anos, em meados de 1801 o governador da província de Goiás decide liberar as zonas proibidas para a exploração dos mineiros mediante a um acordo em que, o ouro poderia ser retirado mediante ao pagamento do quinto ${ }^{3}$, e os diamantes encontrados teriam de ser devolvidos a coroa portuguesa. Segundo Pohl (1986);

Em 1801 o chamado Distrito Diamantino do Rio Claro foi liberado para a exploração do ouro, mas sob a condição de que os diamantes nele achados fossem obrigatoriamente entregues à Coroa a um preço fixado. Por falta de dinheiro, entretanto, em pouco cessou essa entrega e as pedras preciosas achadas ficaram sendo propriedade do povo. (POHL, 1986, p. 136).

Neste período, se desenvolveu uma nova dinâmica populacional na região de Pilões. Esses momentos históricos de Bomfim e Pilões que marcaram o início do povoamento não sofreram um esvaziamento completo de população. O ouro prendia a população. Embora o auge do ouro em Goiás fosse breve, aproximadamente cinquenta anos, a população que antes só se preocupava com o ouro, a partir dos séculos XVIII e XIX com a decadência das minas se inicia uma fase de transição da economia do ouro para a pecuária.

Assim, a mineração, mesmo que com uma fluidez baseada no esgotamento das reservas minerais, fixou núcleos de povoamento no interior do Brasil, nas distantes minas dos Gerais, Mato Grosso e Goiás, especialmente no século XVIII.

Com a retira dos irmãos dois anos após o início da exploração, a zona aurífera do arraial fica proibida, só sendo liberada em 1801, fator que deu um impulso para o povoamento. Em 1833 o arraial de Pilões foi elevado a distrito da capital da província de Goiás (Vilas Boas) e passou a se chamar Distrito Diamantino do Rio Claro.

Com o ouro em decadência, a principal atratividade comercial era a pecuária. Com o declínio do ouro Goiás teve um período de grande decadência. Segundo Chaul (2015), todos os viajantes que percorreram por este momento de transição bem como os historiadores goianos, relatam tal declínio;

\footnotetext{
${ }^{3} \mathrm{O}$ quinto era um imposto cobrado pela Coroa Portuguesa aos mineradores que descobrissem ouro em suas colônias. O total extraído pelo mineiro era derretido, transformado em barra e retirado $20 \%$ do total que seria para a Coroa.
} 
De Silva e Souza (1812) a Cunha Mattos (1823), do dr. Pohl (1810) a SaintHilaire (1816), passando por D'Alincourt (1818), Burchell (1827), Gardner (1836) e Castelnau (1843) e chegando aos historiadores contemporâneos que tratam o período da mineração e da agropecuária em Goiás, além de intelectuais de outras cepas e anônimos da escrita, a aceitação da decadência da sociedade goiana no período pós-minerador é unanime. (CHAUL, 2015, p. 47).

No começo da exploração de Goiás, a preocupação era única e exclusiva com a mineração. A lavoura era menos importante. Os mineiros pretendiam se enriquecer com o minério e afastar-se para o litoral que seria uma região de mais conforto. Segundo Salles (1992, p. 63), “a crise alimentar, decorrente do aumento populacional constante e da irregularidade nos abastecimentos, impeliu a formação de lavouras, que com o correr do tempo passaram a coexistir com as atividades mineradoras". Ainda de acordo com Salles (1992, p. 63);

Formaram-se os sítios de lavouras nas imediações dos povoados, sede dos
mineradores e de suas escravarias. A ocupção das terras se fazia por
concessão de sesmarias, mas o lavrador independente, sem preocupação com
rótulos de propriedade, sem recursos para construir engenhos, apoderava-se
delas à margem da lei, escudando-se na exploração agrícola para construir
sua habitação.

Esta transição do ouro para a pecuária vai se intensificar no século XIX. A região do Distrito Diamantino do Rio Claro continua com a exploração mineral, pois, ainda era encontrado na ociosidade algumas pedras preciosas. O sonho dos mineiros não os deixava ir embora. Salles (2002, p. 96) afirma que "em toda a região aurífera dos rios Claro e Pilões, frequentemente eram encontrados diamantes [...]”. A pecuária na região se tem uma nova ordem a partir do século XX com a chegada de Israel de Amorim no ano de 1926. As regiões mineradoras não eram favoráveis para a agricultura nem para a pecuária. O relevo acidentado juntamente com a pouca produtividade dos solos se opunham a tais industrias.

Em 1924 o povoado passou a ser chamado de Comercio Velho. Vejamos, se iniciou como Bomfim, passou por Pilões, Distrito Diamantino do Rio Claro e agora Comércio Velho. O declínio da população no Comércio Velho já era significativo pelo fato de se encontrar poucos minerais. Porém, com a chegada do Amorim que era capangueiro (comprador de ouro e diamantes) a atenção para a exploração foi retomada. Amorim crescia economicamente e politicamente na região como comerciante. 


\section{Tempos de Ouro: \\ uma análise sobre a formação de Israelândia-GO}

Hyago Ernane Gonçalves SQUIAVE; Dimas Moraes PEIXINHO

Com a proclamação da república em 1889 as terras devolutas do Distrito do Rio Claro são apropriadas pelas oligarquias dos coronéis. Israel de Amorim que começou a ganhar fama quando chegou a região, despertou o alerta nos coronéis em relação as terras. Logo, por pretensões políticas decidiram transferir o povoado de lugar. Para a transferência foi feito um pedido ao então governador de Goiás Pedro Ludovico Teixeira, por parte dos coronéis aproveitando uma ausência do Amorim.

Pedro Ludovico Teixeira decidiu então conceder aos coronéis a transferência do município, mas, para a infelicidade deles, o então governador nomeou Israel de Amorim para ser o articulador do processo de mudança. Este fato causou intriga para com os coronéis. Mas, de fato, o povoado foi transferido para as margens direita do córrego tamanduá, aproximadamente trinta quilômetros de onde o povoado era localizado. A mudança é legalizada pelo decreto-lei 557 de 30 de março de 1938, com a atuação de Israel de Amorim nomeado pelo Dr. Pedro L. Teixeira. O povoado passa a se chamar Itajubá.

Em 1948 o povoado é emancipado com o nome de Iporá, em 19 de novembro. Duzentos anos após a fundação do arraial do Bomfim e Pilões. Mas, neste meio tempo entre a transferência e a emancipação, a família de Fernandinho B. Marquez, por volta de 1942, descobre ouro e diamante em um córrego próximo a onde era o Comercio Velho. Fora denominado de Monchão do $\mathrm{Vaz}^{4}$, ele então se muda com a família e a notícia da descoberta dos metais preciosos faz se erigir um novo povoado.

Este povoado no ano de 1953, através da lei municipal de $\mathrm{n}^{\circ} 54$, foi elevado à categoria de distrito, pertencendo ao município de Iporá. E em 1958 através da lei estadual de n 2.114, o Monchão do Vaz foi elevado a condição de município, recebendo o nome de Israelândia em homenagem a Israel de Amorim, o articulador do processo de emancipação.

Como o espaço e a sociedade está em constante evolução e sendo modificado a cada período técnico, a dinâmica espacial resulta nas relações entre as ações sociais para a transformação do espaço construindo. O primeiro período sendo ouro, cria-se uma cadeia produtiva formando uma dinâmica. Essa dinâmica é incorporada e herdada posteriormente pela lavoura e pecuária como forma de substituir o ouro que, pela sua falta, não conseguia se manter como atratividade comercial.

\footnotetext{
${ }^{4}$ Monchão significa elevação de terra. Vaz era o nome que o córrego fora batizado. 


\section{Tempos de Ouro: \\ uma análise sobre a formação de Israelândia-GO}

Hyago Ernane Gonçalves SQUIAVE; Dimas Moraes PEIXINHO

Sendo assim, o ouro foi o marco inicial para a exploração e fixação de povoados em Goiás, mas, não podemos descartar a lavoura e a pecuária, pois, foi a condição herdada do processo de mineração para a existência do que temos hoje.

\section{CONSIDERAÇÕES FINAIS}

Hoje, nas primeiras décadas de século XXI, muitas dessas cidades, constituídas no ciclo do ouro, estão preservadas e compõem o urbano nacional, não só como monumentos históricos. Por outro lado, muitos dos povoados, prósperos no ciclo do ouro, "desapareceram" ou foram subsumidos em outras dinâmicas espaciais. Essa é a condição do povoado do Arraial do Bomfim (que posteriormente passou a ser denominado Pilões, Rio Claro, Distrito Diamantino do Rio Claro e Comércio Velho), marco inicial do povoamento do município de Israelândia. Pela importância que teve esse povoado e partindo de uma perspectiva geohistória entende-se que ele existe como espaço herdado no atual município de Israelândia, que hoje ocupa o seu sítio urbano.

O povoamento dessa região, que nos seus primeiros tempos, esteve associado ao processo da mineração e assim, ora formavam núcleos, ora esses núcleos eram esvaziados, seguindo um ciclo das descobertas e decadências das minas, nas proximidades do rio Claro. Com o declínio da mineração, por um longo tempo, o povoamento seguiu a lógica da ocupação agropecuária. Dessa forma, percebe-se que os diferentes momentos desse povoar e despovoar, mesmo que por motivações diferentes, vão se constituir nos elementos constitutivos do espaço produzido nessa região, hoje nucleada por municípios da microrregião de Iporá, dos quais Israelândia faz parte.

\section{REFERÊNCIAS}

ABREU, Maurício de Almeida. A apropriação do território no Brasil colonial. In: CASTRO, Iná Elias de; GOMES, Paulo Cesar da Costa; CORRÊA, Roberto Lobato (Orgs). Explorações geográficas: percursos no fim do século. $2^{\mathrm{a}}$ ed. Rio de Janeiro: Bertrand Brasil, 2006.

BASTIDE, Roger. Brasil terra de contrastes. São Paulo: Difusão Europeia do Livro, 1964.

BERTRAN, Paulo. Uma introdução à história econômica do Centro-Oeste do Brasil. Brasília: Codeplan, Goiás: Universidade Católica de Goiás, 1988.

CHAUL, Nasr Fayad. Caminhos de Goiás: da construção da decadência aos limites da modernidade. Goiânia: 4º ed. UFG. 2015.

ISNARD, H. O espaço geográfico. Coimbra: Livraria Almedina, 1982. 
MOREIRA, Ruy. A Geografia serve para desvendar máscaras sociais in: MOREIRA, Ruy (org.) Geografia: Teoria e Crítica. O saber posto em questão. Rio de Janeiro: Editora Vozes, 1982.

PALACÍN, Luís; MORAES, Maria Augusta Santana. História de Goiás. Goiânia: UCG, 1989. História de Goiás. 6ª ed. Goiânia: UCG, 1994.

PEIXINHO, Dimas Moraes. A dinâmica sócio-espacial do modelo técnico-produtivo da sojicultura no Cerrado e a formação dos centros dinâmicos: o caso de Rondonópolis (MT) e Rio Verde (GO). 2006. 320 fls. 2006. Tese de Doutorado. Tese (Doutorado em Geografia) -Universidade Federal do Rio de Janeiro, Rio de Janeiro, RJ. 2006.

POHL, Johann Emanuel. Viagem no Interior do Brasil. Tradução de Milton Amado e Eugênio Amado. São Paulo: ed. Itatiaia. 1976.

PRADO JÚNIOR, Caio. Formação do Brasil contemporâneo. São Paulo: Editora Companhia das Letras, 2011.

SAINT-HILAIRE, Auguste de. Viagem a província de Goiás. Tradução de Regina Regis Junqueira, apresentação de Mário Guimarães - Belo Horizonte. São Paulo. ed. Da Universidade de São Paulo, 1975.

SALLES, Gilka Vasconcelos Ferreira de. Economia e escravidão na Capitania de Goiás. Goiânia: CEGRAF/UFG, 1992.

SANTOS, Milton; SILVEIRA, María Laura. O Brasil: território e sociedade no início do século XXI. $4^{\mathrm{a}}$ ed. Rio de Janeiro: Record, 2002.

SANTOS, Milton. Metamorfoses do espaço habitado: fundamentos teóricos e metodológicos da geografia. 6. ed. 2. reimp. São Paulo: Editora da Universidade de São Paulo, 2014.

Técnica, espaço, tempo: globalização e meio técnico-científico informacional. Editora Hucitec, 1985.

SANTOS, Joaquim Felício dos. Memórias do distrito diamantino. 5. ed. Petrópolis: vozes. Brasília, 1978.

SILVA, Colemar Natal e. História de Goiás. Goiânia: IGL, AGEPEL, 2002.

SILVEIRA, María Laura. O Brasil: Território e sociedade no início do século 21 - a história de um livro. 2011. 